\title{
Crew Health and Performance Improvements with Reduced Carbon Dioxide Levels and the Resource Impact to Accomplish Those Reductions
}

\author{
John T. James Valerie E. Meyers, Walter Sipes, Robert R. Scully and Christopher M. Matty \\ NASA John Space Center, Houston, 77058, USA
}

Carbon Dioxide $\left(\mathrm{CO}_{2}\right)$ removal is one of the primary functions of the International Space Station (ISS) atmosphere revitalization systems. Primary $\mathrm{CO}_{2}$ removal is via the ISS's two Carbon Dioxide Removal Assemblies (CDRAs) and the Russian Carbon Dioxide removal assembly (Vozdukh); both of these systems are regenerable, meaning that their $\mathrm{CO}_{2}$ removal capacity theoretically remains constant as long as the system is operating. Contingency $\mathrm{CO}_{2}$ removal capability is provided by Lithium Hydroxide (LiOH) canisters, which are consumable, meaning that their $\mathrm{CO}_{2}$ removal capability disappears once the resource is used.

With the advent of 6 crew ISS operations, experience showing that CDRA failures are not uncommon, and anecdotal association of crew symptoms with $\mathrm{CO}_{2}$ values just above $4 \mathrm{mmHg}$, the question arises: How much lower do we keep $\mathrm{CO}_{2}$ levels to minimize the risk to crew health and performance, and what will the operational cost to the CDRAs be to do it? The primary crew health concerns center on the interaction of increased intracranial pressure from fluid shifts and the increased intracranial blood flow induced by $\mathrm{CO}_{2}$. Typical acute symptoms include headache, minor visual disturbances, and subtle behavioral changes. The historical database of $\mathrm{CO}_{2}$ exposures since the beginning of ISS operations has been compared to the incidence of crew symptoms reported in private medical conferences. We have used this database in an attempt to establish an association between the $\mathrm{CO}_{2}$ levels and the risk of crew symptoms.

This comparison will answer the question of the level needed to protect the crew from unacceptable risk of acute effects. As for the second part of the question, operation of the ISS's regenerable $\mathrm{CO}_{2}$ removal capability reduces the limited life of constituent parts. It also consumes limited electrical power and thermal control resources. Operation of consumable $\mathrm{CO}_{2}$ removal capability ( $\left.\mathrm{LiOH}\right)$ uses finite consumable materials, which must be replenished in the long term. Therefore, increased $\mathrm{CO}_{2}$ removal means increased resource use, with increased logistical capability to maintain necessary resources on board ISS. We must strike a balance between sufficiently low $\mathrm{CO}_{2}$ levels to maintain crew health and $\mathrm{CO}_{2}$ levels which are operationally feasible for the ISS program.

\section{Nomenclature}

$\begin{array}{ll}B M D & =\text { Benchmark Dose } \\ B M D L & =\text { Lower 95\% confidence on BMD } \\ C D R A & =\text { Carbon Dioxide Removal Assembly } \\ \mathrm{CPT} & =\text { Continuous Performance Task } \\ C T B & =\text { Cargo Transfer Bag } \\ D A B & =\text { Desiccant Absorbent Bed } \\ I S S & =\text { International Space Station } \\ M C A & =\text { Major Constituent Analyzer } \\ \text { ORU } & =\text { Orbital Replacement Units } \\ P M C & =\text { Private Medical Conference } \\ \text { USOS } & =\text { United States Operating Segment }\end{array}$

\section{Introduction}

$\mathrm{R}$ EMOVAL of carbon dioxide $\left(\mathrm{CO}_{2}\right)$ from the atmosphere of any human-occupied spacecraft is an important problem. Humans generate $\mathrm{CO}_{2}$ at a rate of $0.9-1.2 \mathrm{~kg}$ per day ${ }^{1}$ and may experience subtle acute symptoms at concentrations somewhat below $1.0 \%(7.6 \mathrm{mmHg}){ }^{2,3}$ It is not feasible to achieve earth-normal levels of about 0.3 $\mathrm{mmHg}$ in spacecraft. The key question is what acute symptoms could arise as a result of $\mathrm{CO}_{2}$ exposure that could 
affect crew performance and well being, and at what exposure levels (concentration and time of exposure) do these effects occur? We will focus our attention on acute exposure histories of 7 days or less with the understanding that prolonged exposures to moderate levels of $\mathrm{CO}_{2}$ could cause lasting adverse effects. The issue is confounded by the possibility that the fluid shifts present in astronauts increase susceptibility to $\mathrm{CO}_{2}$-induced effects and this is not easy to model in ground-based studies. Furthermore, there are likely to be substantial inter-individual differences in susceptibility to $\mathrm{CO}_{2}$ exposures, so that concentrations transparent to some crewmembers may have a distinct effect on other crewmembers. Thus, we are faced with the necessity of using in-flight data from a heterogeneous population in an attempt to discern if subtle adverse effects can be associated with increases in $\mathrm{CO}_{2}$ levels. If such an association can be found, then we may be able to develop a dose-response curve from which we can estimate the level of control we must exert over $\mathrm{CO}_{2}$ exposures.

Assuming we can estimate risks, at least for some effects, we may then ask what resources must be consumed in order to achieve a specific level of risk. This is an important question for near-earth vehicles such as the International Space Station (ISS) because of the cost of supplying resources will increase as we attempt to manage $\mathrm{CO}_{2}$ concentrations to lower levels. Our goal in this paper is to illustrate how to estimate the resource cost to achieve a targeted level of control of $\mathrm{CO}_{2}$ exposure. For example, how many more resources will be required to manage $\mathrm{CO}_{2}$ levels to $2 \mathrm{mmHg}$ than $3 \mathrm{mmHg}$, or $4 \mathrm{mmHg}$ ? We can also estimate the risk of adverse effects if $\mathrm{CO}_{2}$ levels cannot be well controlled because of hardware failure.

If wise $\mathrm{CO}_{2}$ management aboard the ISS is important, then it will be absolutely critical for exploration class missions where resupply is not possible. Undertaking such long-duration missions will be challenging under any circumstances; however, we cannot allow accumulation of $\mathrm{CO}_{2}$ to affect crew behavior and performance. Yet the cost of over managing $\mathrm{CO}_{2}$ will be tremendous in an exploration vehicle. Thus, we must have a reasonably precise estimate of the effects of $\mathrm{CO}_{2}$ on the crewmembers that will live in such a vehicle. This means that we must consider screening for susceptibility to $\mathrm{CO}_{2}$ in the crew selection process.

\section{A. Record of $\mathrm{CO}_{2}$ Concentrations aboard the ISS}

\section{Approach}

The major constituent analyzer (MCA) provides data that can be used to estimate $\mathrm{CO}_{2}$ levels and these levels are available from the earliest days of ISS operations. Data were available to us as 10-minute average concentrations. Measurements are taken from selected modules and generally the distribution of $\mathrm{CO}_{2}$ concentrations is fairly uniform. However, at times and in certain locations $\mathrm{CO}_{2}$ levels can go well above the levels measured by the MCA. If crewmembers are working in a location with suboptimal air flow, then local concentrations at the breathing zone can be somewhat higher than the module average. Thus, the MCA data are not perfect measurements of crew exposure, but they are reasonably representative when averaged over a day or week.

The range of concentrations found in ISS modules sometimes averages less than $2 \mathrm{mmHg}$ and at other times it exceeds $5 \mathrm{mmHg}$ (see figure 1a and $\mathrm{b}$ ).

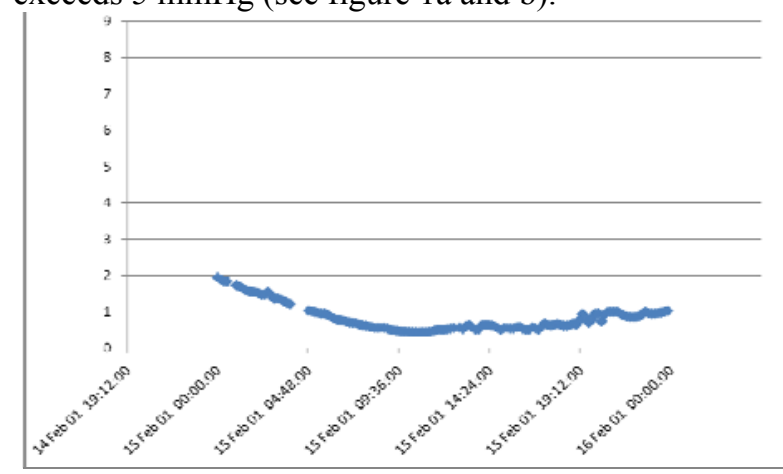

Figure 1a. One day of $\mathrm{CO}_{2}$ concentrations during a time of relatively low $\mathrm{CO}_{2}$ concentrations aboard the ISS.

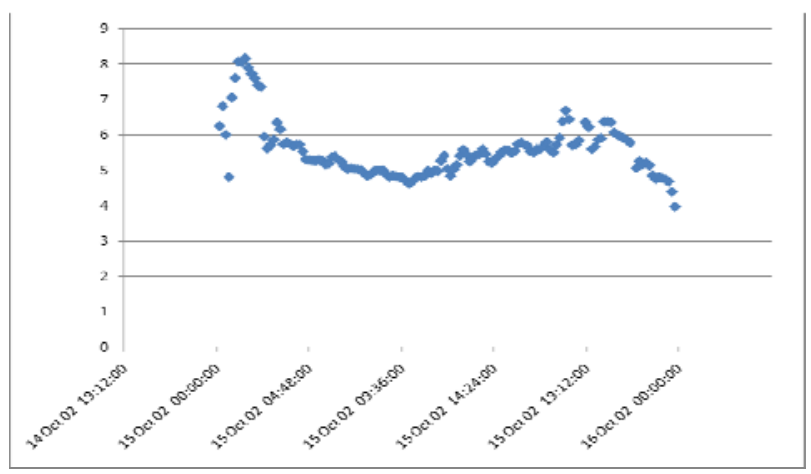

Figure $1 \mathrm{~b}$. One day of $\mathrm{CO}_{2}$ concentrations during a time of relatively high $\mathrm{CO}_{2}$ concentrations aboard the ISS

\section{B. Data Reported on Headaches}


Discovering and capturing subtle effects of any exposure challenges investigators even in well-controlled studies. During operations of the ISS, crewmembers are obviously exposed to $\mathrm{CO}_{2}$ concentrations well above earth normal. In addition, the stress and loss of gravity cause a number of adverse effects on crewmembers throughout the mission. Most of the acute effects unassociated with $\mathrm{CO}_{2}$ disappear within a week of experiencing microgravity, so we excluded adverse effects reported by a crewmember within a week of arrival on orbit. We searched for effects that would be relatively specifically reported in private medical conferences (PMCs) and came up with two: visual effects and headaches. Only headaches were reported often enough to be a useful index of an effect that could be associated with $\mathrm{CO}_{2}$ exposures, and these have been associated with high $\mathrm{CO}_{2}$ exposures in ground-based studies . ${ }^{4}$

We compared the frequency of reported headaches to no reported headache during PMCs with the average $\mathrm{CO}_{2}$ concentrations during the period 7-days before each report and during 24 hours before the report. We also compared the highest $\mathrm{CO}_{2}$ concentrations in the previous 24 hours to the incidence of PMC-reported headaches. We blocked the data in groups as follows: $<2 \mathrm{mmHg}, 2-3 \mathrm{mmHg}, 3-4 \mathrm{mmHg}$, and $>4 \mathrm{mmHg}$.

\section{Data Reported on Behavioral Effects}

The WinSCAT system has been used for several years aboard the ISS to assess behavioral parameters. ${ }^{5}$ Some very limited ground-based studies have shown transient, subtle visual effects from $\mathrm{CO}_{2}$ at concentrations as low as 5 $\mathrm{mmHg}^{2,3}$. We wanted to use WinSCAT test data, some of which depends on visual integrity, to see if there was an association between behavioral performance and higher $\mathrm{CO}_{2}$ levels. Environmental factors are known to affect WinSCAT results. ${ }^{5,6}$ We used a two tier approach in comparing behavioral data to $\mathrm{CO}_{2}$ levels as follows: 1) total raw and differential (preflight vs. in flight $=\Delta$ ) WinSCAT scores, and 2) four throughput sub-scores as raw and differential scores. The four sub-scores were as follows: Mathematical Processing (twenty 3 item addition/subtraction problems), Continuous Performance Task (CPT, 160 one second back numerical memory task), Code Substitution Delayed Recognition (eighteen delayed memory items after 72 stimulus items) and Match to Sample (twenty block design matching items).

We searched for an association between $\mathrm{CO}_{2}$ and behavioral test changes using a scatter gram and linear fit to the behavioral scores. We compared 1-day and 1 week average pre-test $\mathrm{CO}_{2}$ levels to the raw and differential scores of the composite WinSCAT score and to each of the four sub-test scores.

\section{Benchmark Dose Analysis}

The Environmental Protection Agency has developed benchmark dose software (BMD, version 2.1.2) to facilitate the estimation of risk based on dose-response data. Typically, one seeks a low response rate or risk to protect against a specific adverse effect such as headache or visual disturbance. The usual application is to begin with a set of well known exposure levels, and then measure the range of some adverse effect at each exposure level. The data we have are not ideal. We have a mean dose $\left(\mathrm{CO}_{2}\right.$ concentration in each interval) and standard deviation and only one response point (the percent of the time of a response reported in a PMC or WinSCAT) for each mean concentration. None the less, the curve fitting can be accomplished and can inform us of the concentration where we can expect a certain risk of an adverse effect. In addition, the modeling provides an estimate of the $95 \%$ lower bound on the benchmark dose (BMDL).

\section{E. Estimating Resource Needs}

The $\mathrm{CO}_{2}$ scrubbing system for the United States Operating Segment (USOS) consists primarily of the 2 CDRAs. CDRA is a swing-bed type $\mathrm{CO}_{2}$ removal system which uses zeolite as an adsorbent material, and evacuates adsorbed $\mathrm{CO}_{2}$ to space vacuum. One CDRA was designed for $\mathrm{CO}_{2}$ removal for 4 crew, plus 1.25 human crew equivalent worth of animals, although actual flight data has shown that a single CDRA can sustain $<5.3 \mathrm{mmHg}$ (10.2 psia) $\mathrm{CO}_{2}$ partial pressure for up to 9 crewmembers. ${ }^{7}$ Based on historical flight data, the rule of thumb is 6 crew per CDRA, which allows for levels around $4 \mathrm{mmHg} \mathrm{CO}$ partial pressure. With both $\mathrm{CDRAs}$ and Vodzdukh operating, $\mathrm{CO}_{2}$ can be brought below $2 \mathrm{mmHg}$ (fig $1 \mathrm{~b}$ ), although this is extremely resource intensive.

CDRA operation requires electrical power and thermal heat load shedding, Each CDRA requires approximately $900 \mathrm{~W}$ of electrical power and 200-1000W of heat load rejection to the ISS thermal control system. Because both electrical power and thermal load are limited resources on ISS, any resources used by CDRA must be taken from other operational systems or scientific payloads. Therefore, it is important that CDRA only operate as much as is necessary for crew comfort and health. 
Additionally, each CDRA consists of multiple orbital replacement units (ORUs) which have limited lives. These include the 2 CDRA desiccant adsorbent bed assemblies (DAB), a Blower/Precooler assembly, and 6 individual valves. Each of these components has a limited life after which it must be replaced to maintain CDRA operation, most notably the DABs. Each DAB weighs approximately $90 \mathrm{lbs}$ and 5 Cargo Transfer Bags (CTB) equivalent volume, one CTB equivalent being a standard of NASA cargo operations equal to approximately $1.6 \mathrm{ft}^{3}$. Because of this weight and volume, CDRA DABs are highly resource intensive to fly. CDRA DABs currently have a limited life due to internal Zeolite Dust accumulation leading to eventual flow occlusion. ${ }^{7}$ The exact life varies between individual units, but averages less than 2 years of nominal operations before the DAB needs replacement. Current re-designs are in the work to mitigate this problem, ${ }^{8}$ but until this problem is solved the CDRA must be used judiciously to preserve DAB life.

\section{Results and Discussion}

\section{A. Benchmarking $\mathrm{CO}_{2}$ Concentrations and Incidence of Headaches}

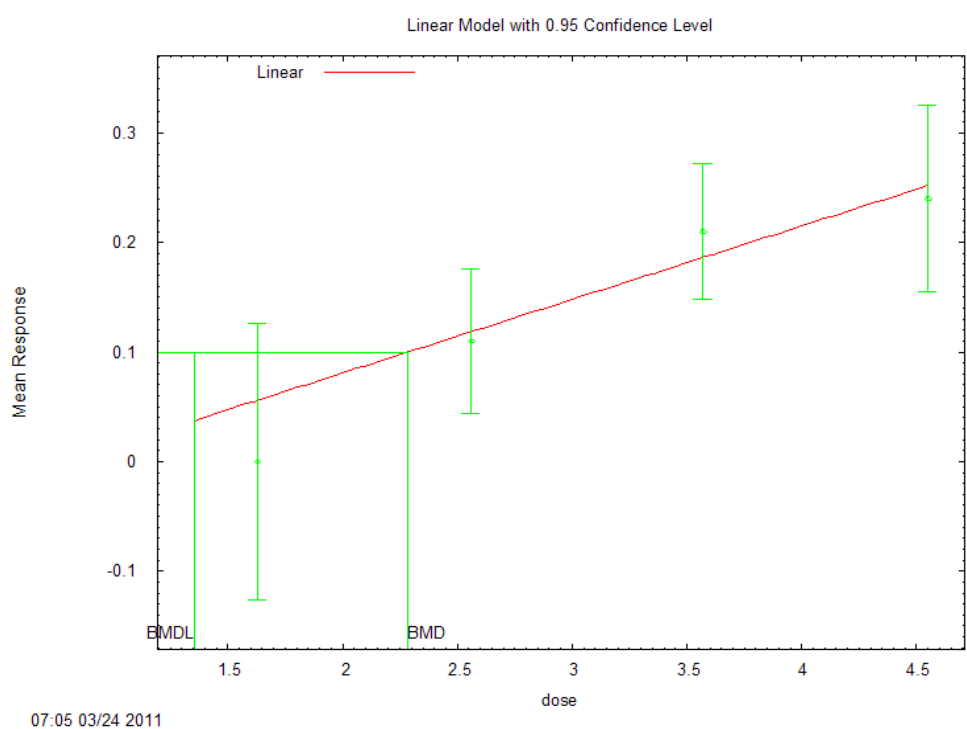

Figure 2. Benchmark-dose analysis of average $\mathrm{CO}_{2}$ dose compared to statistically-transformed percentage of headaches as reported in PMCs. A linear model was used.
An example of the benchmark dose application to the association we found between PMC-reported headaches and 24-hour average $\mathrm{CO}_{2}$ levels (dose) within the four ranges is shown in figure 2. Since percentages are not normally distributed, the percent response levels were transformed to a normal distribution using arcsine of the square root of the decimal percentage such that a mean response of 0.1 is equivalent to a risk of approximately $1 \%$ that a headache will be reported during a given PMC. In this example the maximum likelihood value (BMD) is $2.3 \mathrm{mmHg}$ and the lower $95 \%$ confidence interval (BMDL) is about $1.4 \mathrm{mmHg}$. Two other models (power and polynomial) gave similar BMDs to the example shown here, but their BMDLs were much lower.

A mean response on the transformed scale of 0.2 is approximately a probability
g of the prevalence of headaches and $\mathrm{CO}_{2}$ of $4 \%$ that a headache will be reported during a PMC. Additional modeling of the prevalence of headaches and $\mathrm{CO}_{2}$
exposures are expected when further data on headaches are obtained. For example, the above analysis is weakened by the fact that there were only $20 \mathrm{PMCs}$ that had a 24-hour average $\mathrm{CO}_{2}$ value below $2 \mathrm{mmHg}$. Thus the data point at an average of $1.6 \mathrm{mmHg}$ in figure 2 is not firmly established because with only 20 observations we have a low probability of detecting even a single headache if the true incidence is below $5 \%$. Since we are operating the ISS at lower $\mathrm{CO}_{2}$ levels than in previous years, it is likely that we will accumulate experience in the sub $2 \mathrm{mmHg}$ range.

We are also seeking additional insight into the dose-response relationship between the incidence of headaches and exposure to $\mathrm{CO}_{2}$ by searching for reports of headaches outside the domain of PMCs. We are looking for specific astronauts that might be particularly sensitive to $\mathrm{CO}_{2}$. The reality is that over more than a decade of ISS operations the dozen headaches reported during PMCs is not a serious health concern, although the astronaut's ability to perform complex tasks would be compromised with anything more than a very mild headache. It is also possible that astronauts simply take an analgesic to relieve mild headaches and never report these during a PMC.

\section{B. Associations in Behavioral Data}

None of the behavioral parameters yielded a convincing response to higher $\mathrm{CO}_{2}$ levels, although the $\Delta \mathrm{CPT}$ scores at first seemed promising when we used only the changes above the threshold value for significant change

4

American Institute of Aeronautics and Astronautics 
(figure 3). Initially, we examined only the changes in score above the clinically-relevant threshold of 8 units; however, further discussion and a statistical consultation suggested that we should look at all scores of those astronauts who showed any scores above the clinically-relevant threshold. Once we did that (figure 4) it was apparent that we could not associate group changes in $\triangle \mathrm{CPT}$ with increased exposures to $\mathrm{CO}_{2}$ over the preceding 24 hours. Furthermore, we could not identify individual astronauts who seemed to be consistently responsive to higher $\mathrm{CO}_{2}$ levels. Comparison of these figures illustrates the challenge of finding meaningful associations between variables when many confounding factors are involved.
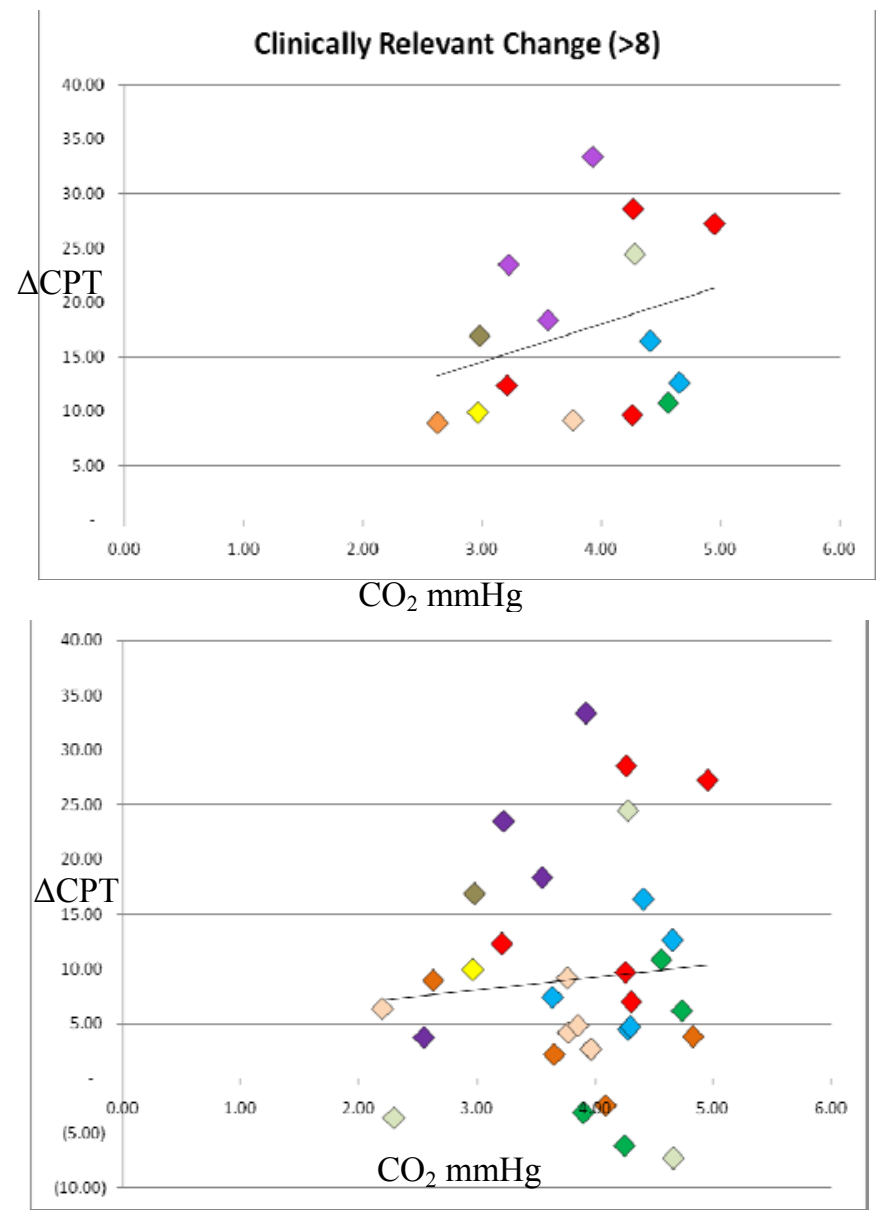

Figure 3. Initial look at the $\triangle \mathrm{CPT}$ score vs. $\mathrm{CO}_{2}$ concentrations for nine astronauts; each one is shown in different colors. The line suggests the possibility of an association of increased $\triangle \mathrm{CPT}$ scores with increasing $\mathrm{CO}_{2}$ concentration.
Figure 4. When all $\triangle \mathrm{CPT}$ scores are considered, including those below the clinically-relevant threshold of 8 , there is clearly no association demonstrated between the score and $\mathrm{CO}_{2}$ exposures

\section{Estimates of Resource Needs}

Operating one CDRA combined with the Russian Vozdukh system currently results in $\sim 3 \mathrm{mmHg}$ pp $\mathrm{CO}_{2}$ average, depending on current crew activity. This is typically the assumed nominal operating posture in the time between docked Space Shuttle missions, when ISS crew consists of 6 individuals. The second CDRA can be activated temporarily for anticipated times of high $\mathrm{CO}_{2}$ loading such as docked shuttle missions. Given current operational capability, maintaining $\mathrm{CO}_{2}$ below 3 for extended periods of time for 6 crewmembers would require two operating CDRAs. The power, heat shedding, and up-mass demands may be too high for practical operations.

As stated in section II E, the CDRA is currently limited by a DAB life of $<2$ years, and DAB replacements are highly resource intensive. The DAB fleet currently consists of 6 cores, with 2 cores required per operating CDRA. Therefore having two CDRAs in operational condition on board ISS requires 4 DAB cores be on board at any given time. The DABs are currently in their $3^{\text {rd }}$ design generation, with a $4^{\text {th }}$ generation in process. The 2 DAB cores remaining on the ground will have $4^{\text {th }}$ generation modifications applied, at which time they will be flown and installed into one of the CDRAs. Ideally, the design changes made to the $4^{\text {th }}$ generation DABs will allow a much longer operational life than the current $<2$ years, but that remains to be verified in operation. Once two of the $3^{\text {rd }}$ generation DABs have been replaced by $4^{\text {th }}$ generation DABs, they can theoretically be returned to the ground and 
rebuilt as a second set of $4^{\text {th }}$ generation DABs. However, at the current time the Space Shuttle is the only vehicle with sufficient cargo capability to return hardware as large as a CDRA DAB. Once the Space Shuttle undergoes planned retirement in 2011, future CDRA DAB design iteration will be dependent on as-yet unidentified spaceflight capability.

Limited $3^{\text {rd }}$ generation DAB life, combined with uncertain future capability to return hardware from ISS, means that operating 2 CDRAs simultaneously for extended periods would have high risk implications.

\section{Conclusions}

We are in the middle stage of searching for subtle adverse effects of $\mathrm{CO}_{2}$ exposure during stays aboard the ISS. The data we have at this point suggests that maintaining a $\mathrm{CO}_{2}$ level of $2-2.5 \mathrm{mmHg}$ will result in a $1 \%$ risk that headaches could be reported during a PMC and a $4 \%$ risk if kept at $\sim 4 \mathrm{mmHg} \mathrm{CO}_{2}$. Although lower $\mathrm{CO}_{2}$ is always considered better, operational limits below $3 \mathrm{mmHg} \mathrm{CO}$ are not practical from a hardware standpoint.

\section{Acknowledgments}

We thank Charles Minard, Mary Wear, Kim Seaton, and Kelley Slack of Johnson Space Center for compilation of parts of the data.

\section{References}

${ }^{1}$ James, J. T. and Coleman, M.E. "Toxicology of Airborne Gaseous and Particulate Contaminants in Space Habitats," Space Biology and Medicine, edited by A. Nicogossian, S.R. Mohler, O.G. Gazenko, and A.I. Grigoryev.AIAA, Washington, 1994, pp. 37-60

${ }^{2}$ Sun, M., Sun, C. and Yang, Y. "Effect of Low Concentration $\mathrm{CO}_{2}$ on Stereoacuity and on Energy Expenditure. Aviat. Space Environ. Med. Vol. 67, No. 1, 1996, pp. 34-39

${ }^{3}$ Yang, Y., Sun, C. and Sun, M. "The Effect of Moderately Increased $\mathrm{CO}_{2}$ Concentrations on Perception of Coherent Motion." Aviat. Space Environ. Med. Vol 68, No. 3, 1997, pp. 187-191

${ }^{4}$ Menn, S.J., Sinclair, R.D. and Welch, B.E. "Effect of Inspired $\mathrm{PCO}_{2}$ Up to $30 \mathrm{mmHg}$ on Response of Normal Man to Exercise," J. Appl. Physiol. Vol. 28, No. 5, 1970, pp. 663-671

5 Kane, R.L. Short, P., Sipes, W. and Flynn, C.F., "Development and Validation of the Space-flight Cognitive Assessment Tool for Windows (WinSCAT), Aviat., Space Environ. Med. Vol 76, Suppl. 6, 2005, pp. B183-B189.

6 Banderet, L.E. Kane, R.L. and Muza, S.R., "Time Course of Cognitive Performance after Ascent to $4300 \mathrm{~m}$, Presented at APA's annual midyear symposium, division 19, Military Psychology (2002).

${ }^{7}$ Reysa, R.P., Lumpkin, J.P., El Sherif, D., Kay, R., Williams, D.E., "International Space Station (ISS) Carbon Dioxide Removal Assembly (CDRA) Desiccant/Adsorbent Bed (DAB) Orbital Replacement Unit (ORU) Redesign,"International Conference on Environmental Systems, ICES 2007-01-3181, Society of Automotive Engineers, Warrendale, PA

${ }^{8}$ Matty, C.M. “Overview of Carbon Dioxide Control Issues During International Space Station/Space Shuttle Joint Docked Operations," International Conference on Environmental Systems, ICES 2010, AIAA, Washington, D.C. 